\title{
Vepsakeelsest kirjandusest
}

\author{
Enn Ernits
}

doi:10.7592/PS/28-6ernits

Teesid: Kirjutises võetakse vaatluse alla vepsakeelne trükisõna funktsionaalsest liigitusest lähtuvalt. Vepsa kirjanduse eelperioodil (1853-1931) ilmus ühtekokku kuus vepsakeelse tekstiga teost (neist kolm vepsa raamatut). Esimesel perioodil (19321937) nägi päevavalgust 32 vepsakeelset raamatut. Neist enamiku moodustas õppekirjandus. Vaheperioodil (1938-1988) avaldati ainult neli teadusraamatut.Teisel perioodil (alates 1989. aastast) on publitseeritud 66 vepsakeelset teost. Neist 27 kuuluvad ilu-, 17 õppe-, 9 vaimuliku ja 9 teatmekirjanduse valda. Keskmiselt ilmub kolm vepsakeelset raamatut aastas (osaliselt kakskeelsed). Erinevalt esimesest ajajärgust osutatakse teisel perioodil suurt tähelepanu ilu- ja vaimulikule kirjandusele, sh lastekirjandusele. Alates 1993 ilmub Karjalas kakskeelne ajaleht "Kodima" ja 2011. aastast vepsakeelne lasteajakiri "Kipinä".

Märksõnad: vepsakeelne kirjandus, raamatud, perioodika, kirjanduse funktsionaalne liigitus, ilukirjandus

\section{Sissejuhatuseks}

Vepslased on läänemeresoome keelerühma kuuluv sugulasrahvas. "Eesti entsüklopeedias" toodud 2002. aastal toimunud rahvaloenduse andmeil oli neid 8240. Vepslased elavad peamiselt Karjalas Äänisjärve edelarannal (arvult üle 4800) ning Vepsa kõrgustikul Leningradi oblastis (veidi üle 2000), tunduvalt vähem Vologda oblastis (alla 500) ja mujal. 2010. aasta rahvaloenduse andmeil 
oli vepslasi alles veel 5936 ja vepsa keele valdajaid 3613. Seega oli kümne aastaga rahvaarv kahanenud 28 ja keeleoskajate arv isegi üle 37 \% (Prozes 2012: 32).

Vepsa keelel on kolm murret: Karjalas põhja- ehk äänisvepsa murre, Leningradi ja Vologda oblastis keskmurre ning Leningradi oblastis viimasest lõuna pool lõunavepsa murre. Vepsa kirjakeel põhineb keskmurdel, mida räägitakse kõige laiemal maa-alal. Vepsa kirjasõna ajaloos eristatakse kaht põhiperioodi: 1930. aastatel olnud esimest ja 1989. aastal alanud teist perioodi (Zaitseva 2005b: 181). Lisaks ei saa mööda ka eel- ja vaheperioodist. Vepsakeelse kirjanduse ajaloost 1990. aastate lõpuni on teinud venekeelse sissevaate Karjala teadlased Irina Spiridonova (2000) ja Nina Zaiceva (2000b). ${ }^{26}$ Meil on vepsa kirjandust Karjala kirjanduse osana lühidalt vaadelnud Jaan Õispuu (2003).

Artiklis antakse funktsionaalsest liigitusest lähtuvalt ülevaade XIX sajandi teisest poolest 2011. aasta lõpuni üllitatud vepsakeelsetest ilukirjandus-, tarbe- jt tekstidest. Suuremat tähelepanu pööratakse vepsakeelsetele raamatutele. Nende hulgas mainitakse ka mitmekeelseid sõnastikke ja teaduslikus transkriptsioonis publitseeritud keeleainest. Tähelepanuta on jäänud muukeelsed vepsa keele õpikud ja teadustööd. Väga vähesel arvul vaadeldakse käesolevas kirjutises ajakirjanduses ja raamatutes avaldatud lühitekste (luuletusi, muinasjutte jm). Põgusalt on peatutud vepsa loomingu tõlgetel teistesse keeltesse. Sissevaadet aitab olulisel määral täiendada kirjanduse loetelu, mis on samaaegselt ka vepsa keelt sisaldavate teoste bibliograafiaks. Selleks, et saaks ettekujutust käsitletavate raamatute mahust, on bibliokirjele lisatud lehekülgede arv. ${ }^{27}$ Bibliografeerimisel on peale de visu kontrolli kasutatud interneti vahendusel Karjala Vabariigi Rahvusraamatu elektronkataloogi, kaht bibliograafiat (vt internetiallikad), samuti kõikvõimalikke

26 Vepslaste nimed kirjutatakse käesolevas artiklis vepsa kirjaviisist lähtuvalt $c$ ja ̌̌, mitte ts ja tš abil.

27 Andmete kuhjamise vältimiseks on loobutud illustreerijate ja formaadi märkimisest. Lehekülgede arvu tähistamine on de visu kontrollimise võimaluse sagedase puudumise tõttu ühtlustamata. Mitmel juhul pole teada, kummas keeles pealkiri asub kirjes esikohal. 
allikaid üksikteoste kohta. Tärniga on märgitud need kirjandusallikad, mis pole vepsa raamatud. Nende alla mahuvad eespool mainitud keeleõpikud ja teadustööd, lisaks enamik mitmekeelseid (rohkem kui kaht keelt sisaldavaid) kogumikke, milles vepsa keele osakaal on suhteliselt väike. Muide, erinevalt vepsakeelse kirjanduse mõistest on vepsa kirjandus laiem, hõlmates ka vene ja soome keeles kirjutatut.

\section{Eelperiood}

Vepslased avastas teadusmaailmale soome keeleteadlane Andreas Johan Sjögren suhteliselt hilja, alles 1824. aastal esmakordselt nende juures viibides. Esimese teadustöö vepsa keelest kirjutas eepose "Kalevala" koostaja Elias Lönnrot, kes kogus ainest Äänis-Vepsast ja avaldas rootsikeelse väitekirja pealkirja all "Põhjatšuudide keelest" (Lönnrot 1853: 3-28). ${ }^{28}$ See sisaldas peale keelekirjelduse seitset muinasjuttu vepsa keeles ja nende tõlget soome keelde, lisaks vanasõnu ja mõistatusi tõlgetega ning katkendi Matteuse evangeeliumist (Zaiceva 1981: 9).

Kuus aastat hiljem üllitas soome keeleteadlane August Ahlqvist endakogutud keskvepsa materjalil põhineva "Ülestähendusi põhjatšuudi keelest" (Ahlqvist 1859). Teos sisaldab peale grammatilise ülevaate mitmesuguseid tekste ja väikese vepsa-rootsi sõnastiku. Kümme aastat hiljem avaldas A. Ahlqvist vepsa tekstid ja sõnastiku ka läänemeresoome keelte kogumikus (Ahlqvist 1869: 170188, 239-259). Eelperioodist on teada ka Äänis-Vepsast pärinenud vene rahvusest kooliõpetaja Pavel Uspenski väike vepsa-vene sõnaraamat (Uspenski 1913; vt Inno 1991). See kuulub teatmekirjanduse hulka. Samuti jääb eelperioodi teaduslikus transkriptsioonis publitseeritud kaks köidet lõunavepsa murdetekste, mille kogus ja andis koos tôlgetega välja soome keeleteadlane Lauri Kettunen $(1920,1925)$.

28 Väitekiri on paar korda hiljemgi avaldatud (vt Lönnrot 1991, 2002). 


\section{Esimene periood}

Vepsa kirjakeel loodi 1930. aastate alguses nn kultuurirevolutsiooni laineharjal. Vepslasi oli tollal ainuüksi Leningradi oblastis üle 24 000. Vepsa lapsi õppis 49 alg- ja 5 keskkoolis, kuid kõikjal ei saadud kohe sisse viia emakeele õppimist, sest paljudes kohtades puudusid vepslastest õpetajad. Paraku pidid äänisvepslased nagu karjalasedki kasutama soome keelt (Mullonen 1967: 106, 108; Zaiceva 1989: 129 jj). Esimene vepsa aabits (koos lugemikuga) ilmus 1932. aastal ja eraldi aabits neli aastat hiljem (Bogdanov, Hämäläinen, Mihkijev 1932; Andrejev, Hämäläinen 1936). Seega on vepsa kirjandus ja kirjakeel üsna noored.

Esimesel perioodil koostati põhiliselt algkooliõpikuid. Ühtekokku ilmus Venemaal 31 raamatut. Nende seas oli koos aabitsatega 28 õpikut, millest 9 ópetasid keelt ja kirjandust (Andrejev 1934a, 1934b, 1935, 1937; Andrejev, Bogdanov, Petuhov, Silin 1933; Andrejeva 1936; Bogdanov, Loginov, Bol'šakov jt 1936; Hämäläinen, Andrejev 1934, 1935). Ilmus ka õppekirjandusega seotud, kuid tarbekirjanduse valda kuuluv ilukirja õpetamise programm (Programmad 1937). Keeleõpikute-lugemike autoriteks olid peamiselt vepslasest kooliõpetaja Fjodor Andrejev, vepslasest teadlane, vepsa tähestiku looja Nikolai Bogdanov ning ingerisoomlasest Leningradi ülikooli dotsent Matti Hämäläinen. Stalinismi perioodi lugemikud olid tugevasti üleideologiseeritud. Nende ilukirjanduspalad kujutasid endast peamiselt tõlkeid vene keelest ja olid algkooliõpilaste jaoks kohaldatud.

Mõne aasta jooksul jõuti anda välja ka 10 aritmeetika (Popova 1933a, 1933b, 1934a-d, 1936, 1937a-c), 4 loodusteaduse (Tetyrev 1934, 1935, 1937a, 1937b) ja 3 maateaduse õpikut (Terehova, Erdeli 1934, 1936a, 1936b). Kõik mittekeelealased õpikud olid tõlgitud vene keelest. Peale lugemikes sisalduvate ilukirjandustekstide ilmus vaid üks õhuke tõlkeline juturaamat vähetuntud vene autori sulest (Grigor'jev 1937). Kogu õppekirjandus anti välja Leningradis. 1936. aastal nägi päevavalgust väike vepsa-vene sõnaraamat, mis sisaldas ligikaudu 3000 sõna (Hämäläinen, Andrejev 1936). 
1930. aastate teisel poolel kirjakeele areng järsku katkestati. Järgnesid repressioonid, üleminek vene õppekeelele ja vepsakeelsete õpikute põletamine (Zaiceva 1997: 117). Esimesse perioodi kuulusid ka Soomes Lauri Kettuneni ja Paavo Siro kogutud vepsa tekstid teaduslikus transkriptsioonis koos tõlgetega (Kettunen, Siro 1935).

\section{Vaheperiood}

Järgnevalt eristub vepsa kirjasõna ajaloos pool sajandit kestnud nn vaheperiood (1938-1988), mil Soomes ilmus vaid kaks ja Venemaal üks vepsakeelne, kuid soomeugri transkriptsioonis tekstikogumik tõlgetega. Neist esimese ainestik oli tegelikult kogutud juba XIX sajandi lópul keeleteadlaste E. N. Setälä ja J. H. Kala poolt (Setälä, Kala 1951). Ka vaheperioodi lópu poole välja antud A. Sovijärvi ja R. Peltola tekstid olid kirja pandud juba varem (Äänisvepsän 1982). Leningradisüllitatud tekstikogumiku jaoks olid materjali kogunud kõigist murretest Petroskoi lingvistid Maria Zaiceva ja Maria Mullonen (Zaiceva, Mullonen 1969). Samad keeleteadlased koostasid ka mahuka, üle 700-leheküljelise vepsa-vene sõnaraamatu, taaskord transkriptsioonis (Zaiceva, Mullonen 1972). Sellised, iseenesest väga olulised üllitised, k.a sõnaraamat, mis kuulub teatmekirjanduse hulka, olid mõeldud esmajoones teadlastele. Kogumikes ilmunud tekstidest tahaksin mainida Eestis avaldatud põhja- ja keskvepsa muinasjutte (Ariste 1964) ning Soomes ilmunud vepsa tekste lähissugulaskeelte lugemikus (Virtaranta 1967: 111-136).

\section{Teine periood}

Seoses NSV Liidu lagunemisega hoogustus vepsa liikumine, mille käigus arendati vepsa kirjakeelt ja vepsakeelset kirjandust. See toimus paralleelselt karjala kirjakeelte arenguga (Õispuu 2003: 519). Vepsa kirjakeele taasrajaja oli keskvepslasest Karjala teadlane Nina Zaiceva. Ta tegeleb ulatuslikult ka keeleloomega. Nina Zaiceva on paljude õpikute ja luuletuskogude autor, samuti vaimulike jt teoste 
tõlkija. Toimetajana käib tema käe alt käib läbi peaaegu kogu vepsa kirjasõna.

Teise perioodi stiimuliks ja esimeseks pääsukeseks sai 1989. aastal ajakirja "Punalippu" (praegune "Carelia") vepsateemaline number, milles avaldati muu hulgas ka üht-teist ilukirjanduslikku (Mišin 2005: 194). Nii toimis ka ajaleht toonase nimetusega "Neuvosto-Karjala”.

Ilukirjandust ja rahvaluulet esindavad teisel perioodil, nagu see on noorele rahvuskirjandusele iseloomulik, peamiselt luuleteosed, ühtekokku 17. Temaatikas on tähtsal kohal mure rahva ja keele saatuse pärast, kodupaiga looduse ja emakeele ilu kajastamine ja väärtustamine. Suurem jagu luuletajaid pärineb Keskvepsast. Vepsa luule elavaks klassikuks loetakse Nikolai Abramovit, kelle sulest on ilmunud viis luuletuskogu, mis sisaldavad nii originaal- kui ka tõlkeloomingut: "Kolmkümmend kolm" (1994), "Kurgede aeg" (1999), vepsa- ja venekeelne "Ajame juttu, veli" (2005), vepsa- ja ungarikeelne "Topelt kolmkümmend kolm" (2010a) ning vepsa- ja prantsuskeelne "Metsade laulud" (2011). Esimene luulekogu ilmus, kui luuletaja sai 33-aastaseks. Abramov on valitud nii Venemaa kui ka Karjala Kirjanike Liidu liikmeks (Mišin 2005: 199).

Iseseisva luulekoguga on hakkama saanud veel teisigi, nagu tuntud äänisvepsa muinasjutuvestja Anastasia Logačova tütar Alevtina Andrejeva, kelle vepsa- ja venekeelset luulet sisaldav kogu kannab pealkirja "Kaseke" (Andrejeva 2003). Mihhail Bašnin on avaldanud samuti vepsa- ja venekeelse luulekogu "Vana peegel" (Bašnin 2003) ning Nina Zaiceva "Valge une süles" (Zaiceva 2008). Viimane neist on A. Mišini väitel esmakordselt tõstatanud vepsa luules naise teema (Mišin 2005: 208).

Tähelepanu väärib Soomes elava välisvepslase Raisa Lardot' looming. Autor kirjutab soome keeles peamiselt proosat, kuid 2001. aastal ilmus tema sulest äänisvepsa murdes luulekogu "Jäätunud linnud langevad okstelt" paralleeltõlgetega soome ja vene keelde (Lardot 2001; vt ka Mošnikov 2007).Vepsa poeetide (Maria Abramova, N. Abramovi, A. Andrejeva jt) palu sisaldab ka Kuhmos elava kirjamehe Markku Niemineni koostatud fotoalbum "Kodu- 
kant Vepsamaa" (läheb ka kunstiraamatute kirja), samuti Nina Zaiceva toimetatud "Värske tuul" (Nieminen 2003; Zaiceva 2008). Siinkohal ei saa jätta nimetamata Šoutjärve vepsa muuseumi rajaja Rürik Lonini kogutut, mille ta avaldas raamatus "Lühilaulud ehk tšastuškad" ja segakogumikus "Minu rahva folkloor" (Lonin 2000a; vt ka 2000b). Autoriluulet on avaldatud veel kolmes jutte ja luulet sisaldavas segakogumikus (vt allpool).

Eraldi tuleb kõnelda lastekirjandusest, kuid neile mõeldud luulekogusid on veel üsna kasinalt. Üks neist on N. Zaiceva luulekogu "Armas Liisa" (Zaiceva 2005a). Ka A. Andrejeva kogu sisaldab lasteluulet. N. Zaiceva on tõlkinud Armas Mišini ja E. Kiuru lühendatud eepose "Kalevala lastele ja noorsoole" (Kalevala 2003). L'udmila Melentjeva avaldas vepsa lastelaule nootidega (Melentjeva 1994). Lastele mõeldud luulet ja laule nootidega sisaldab ka noore vepslasest õppejõu Ol'ga Žukova hiljuti ilmunud raamatuke (Žukova 2011).

Vepsa keelde on tõlgitud eri maade luuletajate teoseid, sh Aleksandr Puškini, William Shakespeare'i, Umar Hajjami, Sergei Jessenini jt loomingut. Vepsa luulet on tõlgitud paljudesse keeltesse, teadaolevalt eesti, karjala, komi, mari, mokša, norra, prantsuse, rootsi, soome, vene, udmurdi ja ungari keelde. Eestis on ilmunud Arvo Valtoni ja Jaan Õispuu koostatud kogumik "Kuum öö", milles on muu seas esitatud 11 vepsa luuletaja vepsakeelseid värsse koos Jaan Õispuu tõlgetega ning Jaan Õispuu ja Arvo Valtoni poolt tõlgituna Nikolai Abramovi luulekogu "Kurgede aeg" (Abramov 2010b).

Siirdume nüüd proosa käsitlemisele. Selles vallas on seni ilmunud 7 vepsakeelset teost, lisaks 3 luulet ja proosat sisaldavat segakogumikku. Vepslastel oli aastani 1990 teada kolm andekat proosakirjanikku: Viktor Pulkin, Anatoli Petuhov ja Raisa Lardot (snd Larjuškina), kuid neist kaks esimest kirjutavad vene keeles, Lardot aga soome keeles (vt ka Zaiceva 2005b: 182-184). 1993. aastal Vepsa Kultuuri Seltsi korraldatud kirjandusvõistlusel tuli võitjaks Keskvepsast Pondalast pärinev Viktor Jašov vepsakeelse proosapalaga "Kondi" ('Karu'). Vepsakeelset proosakirjandust on tõlgitud teistesse keeltesse suhteliselt vähe, küllap pole see veel piisavalt küps. 
Vepsa keeles on käesolevaks ajaks ilmunud vaid üks romaan "Kalarand". Selle lõi poolenisti vepsa, poolenisti juudi päritolu noor muusik Igor Brodski Peterburist (Brodski 2002). Muide, Peterburi on Vepsamaast mõneti eraldi seisev vepsa kultuuri saar. Teost esitleti Soomes Kuhmos toimunud vepsa kirjanike esimesel konverentsil 2002. aastal, kus osales 12 vepsa keeles kirjutavat inimest. Armastusromaan "Kalarand" ei vii lugejat traditsioonilisse vepsa külaühiskonda, vaid käsitleb hoopis linnakeskkonda. Raamatut on ajakirja Keel ja Kirjandus veergudel tutvustanud Kristi Salve (2004).

Proosa- ja luulekogumik "Kodukant" oli oluline tähis vepsa noores kirjanduses (Kodirandaine 1996). Huvipakkuvaim selles on Zaiceva tõlgitud vene keeles kirjutava Vassili Pulkini teos "Laps'aigan abekirj" ('Lapsepõlve aabits'). Nimetatud kogumikus ilmus ka eespool mainitud "Kondi" ja muud külaproosat. Mullu ilmus esimene vepsa kirjanduslik almanahh "Värske tuul", milles on vepsa keeles publitseeritud nii originaalset kui ka vene keelest tõlgitud belletristikat, peale selle veel kunsti, olukirjeldusi jm (Verez 2011). Üks segakogumik sisaldab vepsa- ja karjalakeelset loomingut (Ščerbakova, Aleksejeva 2010).

Vepsakeelset kirjasõna sisaldab teiste uurali keelte hulgas kolm paljukeelset kogumikku, nimelt Sõktõvkaris ilmunud "Toomejõgi" (luule ja proosa) ning "Valged ööd" (luule; L'öm ju 2008; Belõje 2010), samuti A. Volkovi ja Armas Mišini kokkupandud "Ugrimaalt Balatonile” (Jugras 2006). Väärtuslikuks abimaterjaliks ilukirjanduskeele rikastamisel on Eesti teadlaste koostatud kaheosaline vepsa vanasõnade raamat neljas keeles vastetega (Vepsa 1992a, 1992b).

Lastele mõeldud raamatutest kuulub proosakirjanduse alla vene keelest tõlgitud Silakova "Tõelised sõbrad" ja "Valge öö" (Silakova 2006, 2009). Mõlemad on vepsandanud ajakirjanik Marina Ginijatullina. On tõlgitud ka üks koomiks "Luhtunud kalalkäik" (Lukkonen 1992). Seega pole originaalset vepsa lasteproosat veel raamatuna ilmunud. Samuti on avaldatud kolm muinasjutukogu, üks neist Lönnroti kogutud muinasjuttudest, mis on Zaiceva tõlkes üllitatud ka soome keeles, ning kaks teist sisaldavad vepsa lugu- 
sid paralleelselt vene tõlgetega (Vepsän 1996; Vepsänman 2006, Iče 2011). Lisaks väärib siinkohal mainimist Karjala Õpetajate Täiendusinstituudi poolt üllitatud väike segakogumik, mis sisaldab peale vepsakeelsete muinasjuttude veel jutustusi ja luuletusi ("Skazki" 1993). Eestlastest on vepsa muinasjutte kogunud, eestindanud ja raamatuna avaldanud Kristi Salve (Vepsa 1993).

Vepsa ilukirjandust ilmub peale raamatute ka ajakirjanduses. Üks kord kuus üllitatakse aastast 1993 neljaleheküljelist ajalehte "Kodima" ('Kodukant'). See on kakskeelne: välimised leheküljed vepsa, sisemised aga vene keeles. Ajalehe algataja ja esimene toimetaja oli Nina Zaiceva. Ajalehes avaldatakse nii ilukirjanduslikke palu kui ka olustikulisi ja päevakajalisi lugusid, nii originaale kui ka tõlkeid (vt ka Salve 1994). Vepsakeelset loomingut avaldavad ka ajakiri "Carelia" (tõsi küll, hilisemal ajal väga vähe) ja lasteajakiri "Kipinä" ('Säde'). Viimane hakkas soome- ja karjalakeelse kõrval mullu ilmuma ka vepsa keeles, nimelt neli 24-leheküljelist numbrit aastas. See on tähtis samm nii vepsa oleviku kui ka tuleviku jaoks. Peale paberile pandud vepsakeelse kirjasõna võib üht-teist leida ka internetist, nagu "Kodima” ja "Kipinä" numbreid jm.

Vepsa keelde on tõlgitud $9 \mathrm{va}$ i mulik ku teost, sh apostlite teod ja neli evangeeliumi (Apostoliden 1999; Evangelii 1993, 1996, 1998; Markan 1992). Üsna paks on värvipiltidega lastepiibel (Lapsiden 1996; vt Jegorova 1997). Kõige mahukam seni ilmunud vepsa ükskeelne raamat onUus Testament ( $\mathrm{Uz}^{\prime}$ Zavet 2006). Selle tõlkimisel oli lähteks soomekeelne Uus Testament. Asjaga tegeles peale tõlkija teoloogilise konsultandina Inka Pekkanen, kes võrdles tõlget kreekakeelse alustekstiga, ja teisi (Pekkanen 2005: 163). Peaaegu kogu vaimuliku kirjasõna on tõlkinud Nina Zaiceva, ainult "Jeesuse elu" on vahendanud Rürik Lonin (Iisusan 1991, 1994). Muide, R. Lonini tõlge on vepsakeelsete raamatute seas teise perioodi esimene pääsuke.

Suhteliselt palju on vaadeldaval ajajärgul ilmunud vepsakeelset õppekirjandust, nimelt 17 raamatut, mis on peaaegu võrreldav luuleraamatute arvuga, kuigi kogumaht tuleb õpikirjanduse kasuks. 1991. aastal ilmus Nina Zaiceva ja Maria Mulloneni koostatud raamatute raamat - kukeaabits, mis on teatavasti aluseks iga- 
sugusele kirjandusele (Zaiceva, Mullonen 1991a). Järgmisel aastal ilmus Šoutjärve keskkooli õpetajate jõupingutuste tulemusel kirillitsas koostatud vepsa aabits (Maksimova, Kottina 1992). See jäi ainukeseks taoliseks katseks.

Lahkuminevalt esimesest perioodist moodustavad vepsakeelse õpikirjanduse põhilise osa vepsa keele materjalid: kaks õpikut (Kukojeva, Ginijatullina2007, 2009), kolm lugemikku (Zaiceva, Mullonen 1991b, 1994; Kottina, Maksimov, Zaiceva 1998), neli töövihikut (Ginijatullina, Kukojeva 2008; Mel'nik 2000, Vepsän 2004; Popova, Zaiceva 2004) ning üks grammatikaharjutuste kogu (Rogozina, Zaiceva 2004). Enamik õppekirjandusest on koostatud algklasside jaoks, vaid vepsa grammatika on mõeldud 5.-9. klassi õpilastele (Zaiceva 2003). J. Kočerina raamat, mis kujutab endast piltsõnastikku grammatika algetega, on mõeldud lastele, kes alles alustavad vepsa keele õppimist (Kočerina 2004). Osa õppevahendeid sobib üliõpilastele, nagu Zaiceva koostatud kaks morfoloogia-alast tööd (Zaiceva 1995, 2000a). Igor Brodski on avaldanud lastele värvitrükis põneva loodusloo lugemiku (Brodski 2000).

Seni on ilmunud 9 nimetust teat mekirjandust. Nende hulgas on 7 kaks- või mitmekeelset sõnastikku, sh 20-leheküljeline keeleteaduse terminite sõnastik, koolisõnastik ning vepsa-vene ja vene-vepsa sõnaraamatud (Brodski 2005; Lingvistine 2001; Školvaihišt 2001; Zaiceva, Mullonen 1995, 2009, 2010; Vepsän 2004). Huvi võiks pakkuda karjala, vepsa ja saami murrete kõrvutav sõnaraamat (Sopostovitel'no 2007). Ilmavalgust nägi ka esimene, N. Zaiceva ja O. Žukova koostatud kakskeelne vene-vepsa vestmik (Venä-vepsläine 2009). Suhteliselt piiratud arvul sisaldab vepsakeelses vestluses kasutatavaid lauseid juba varem Eestis ilmunud 19-keelne "Uurali keelte sõnastik" (2004, 2011).

Vepsa keeles ilmus 2008. aastal esimene pääsuke ka teabek i r jandusest, nimelt üsna paks, 250-leheküljeline, kuid väikeses formaadis "Vepslased", mis annab ülevaate keelest, elupaikadest, ajaloost, usundist ning vaimsest ja materiaalsest kultuurist (Strogalščikova2008). Selle autor on vepslasest Petroskoi teadur Zinaida Strogalščikova. A i me - ja samaaegselt kunstikirja nduse hulka võib paigutada Soomes ilmunud fotoalbumi Vepsamaast, mis sisal- 
dab ka lühikest ajaloo ülevaadet (Savolainen 1998). Vähese vepsakeelse tarbekirjanduse hulka kuuluvad O. Žukova tõlgitud inimõiguste deklaratsioon ja suureformaadiline värvitrükis üllitatud 2009.-2010. aasta kalender (Mehen 2009; Vepsläine 2009).

\section{Kokkuvõtteks vepsakeelsete raamatute kohta}

Vepsakeelse kirjanduse eelperioodil (1853-1931) ilmus ühtekokku kuus vepsakeelset teksti sisaldavat teost (5 Soomes ja 1 Venemaal). Neist kolme saab pidada vepsa raamatuks, millest üks kuulus teatmekirjanduse, kaks teaduskirjanduse valda. Vepsa kirjanduse esimesel perioodil (1932-1937) nägi päevavalgust 32 vepsakeelset raamatut (31 Venemaal ja 1 Soomes). Neist enamiku (28) moodustas õppekirjandus, ülejäänud kolm raamatut esindasid teadus-, teatme- ja tarbekirjandust. Aastas avaldati keskmiselt 4,6 raamatut. Vaheperioodil (1938-1988) avaldati nii Soomes kui ka Venemaal üpris vähe, nimelt kummaski kaks teadusraamatut.

Teisel perio odil (alates 1989. aastast) on peaaegu veerandsajandi jooksul avaldatud 66 vepsakeelset raamatut. Neist 27 kuuluvad ilu-, 17 õpi-, 9 vaimuliku, 9 teatme-, 2 tarbe-, 1 teabe- ja 1 aimekirjanduse valda. Ilukirjandusteostest 17 on pühendatud luulele, 7 proosale ja 3 on segakogumikku. Aastas on trükitud 1-8 raamatut, v.a 1997. aastal, mil ei ilmunud ühtki teost. Keskmiselt tuleb aasta kohta kolm vepsakeelset raamatut. Seega on vepsa kirjandus täiesti olemas ja muutub üha mitmekesisemaks. Erinevalt esimesest ajajärgust osutati teisel perioodil peale kooliliteratuuri suuremat tähelepanu ilu- ja vaimulikule kirjandusele. Praegu puudub teadaolevalt veel teaduskirjandus. Luule- ja muinasjutukogud ilmuvad sageli paralleelselt vepsa ja mõnes teises, sagedamini vene keeles. Võrreldes esimese perioodi omadega on tänapäeva vepsa raamatud välimuselt kenad. Nende tiraaž on üsna erinev, nt lastepiiblit trükiti 5000 eksemplari, luulekogusid aga tavaliselt 500-1000. Kirjanduse väljaandmisel on abi osutanud Karjala Vabariik, Soomes Kuhmos tegutsev Juminkeko-fond, Castréni Selts jt. 
NSV Liidu kui impeeriumi lagunemine võimaldas veel üsna hilja, nimelt XX sajandi lõpul Venemaa väikerahvaste ärkamise ja endamärkamise, oma keele ja kultuuri arendamise ning tulevikulootuste hellitamise. Kuigi vepslaste arv drastiliselt kahaneb, ei ilmne kirjanduses veel raugemise märke, pigem vastupidi. Suurt rõhku pannakse lastekirjandusele. See on eriti positiivne. Kui kaua kirjanduse üsna hoogne areng kestab? Seda ei tea kindlalt paraku keegi. Mulle tundub, et käes on vepsa kirjanduse sügis, ja see on kuldne.

\section{Internetiallikad}

Бродский, И. В. Vepsänkel'židen kirjoiden bibliografii = Books in Vepsian - bibliography = Библиография книг на вепсском языкепо состоянию на 1.10.2007 г.

Internetis: http://www.oocities.org/meidenkodima/bibliografii.htm (vaadatud märts 2012).

Joalaid, Marje. Vepslastest ja vepsa keelest. - Fenno-Ugria Asutus.

Internetis: http://www.fennougria.ee/index.php?id=19761 (vaadatud märts 2012).

Национальная библиотека Республики Карелия.

Internetis: http://library.karelia.ru/cgi-bin/library/ecatalog.cgi (vaadatud märts 2012).

\section{Kirjandus}

Abramov, Nikolai 1994. Koumekümne koume: Runokirj. Redaktor Nina Zaiceva. Känzi Irina Kart. Petroskoi: Karjala. - 54 lp.

Abramov, Nikolai 1999. Kurgiden aig: Runod . Redaktor N. Zaiceva. Petroskoi: Periodika. - 64 lp.

Abramov, Nikolai 2005. Pagiškam, vel'l' $l^{\prime}$ Поговорим, брат: Сборник стихов. Petroskoi: Periodika. - $112 \mathrm{lp}$. 
Abramov, Nikolai 2010a. Kahtisti koumnekümne koume: runokogomuz vepsän $i$ vengrian kelil = Kétszer harminchárom: Válogatott versek vepsze és magyar nyelven. Válogatta és fordította Nagy Katalin. Budapest: Pyteas. - 172 p.

*Abramov, Nikolai 2010b. Kurgede aeg. Tlk. Jaan Õispuu, Arvo Valton. Toim. Arvo Valton. Tallinn: Kirjastuskeskus. $-64 \mathrm{lk}$.

Abramov, Nikolai 2011. Les chants des forêts: Edition bilingue. Poèmes choisis, traduits du vepse et présentés par Sébastien Cagnoli. (Poésies ouraliennes; 4) Paris: Adéfo. -74 p.

*Ahlqvist, August 1859. Anteckningar i Nord-Tschudiskan. (Acta Societatis Scientiae Fennicae; 6.) Helsingfors. -64 lp.

*Ahlqvist, August 1869. Suomalainen murteiskirja tahi lukemisia Viron, Karjalan, Vatjan, Vepsän ja Liivin kielillä suomalaisten sanastojen kanssa. Helsinki. $-8,274 \mathrm{~s}$.

Andrejev, F. A. 1934a. Literaturnij hrestomatij vepskijale nacal'nijale şkolale: Kuumanz' openduz voz'. Leningrad: Kirja. - 82 lp.

Andrejev, F. A. 1934b. Vepskijan grammatikan openduzkirj ez'maizele i toizele klassale vepskijas nacal'nijas şkolas. Leningrad: Kirja. - 49 lp.

Andrejev, F. A. 1935. Literaturnij hrestomatij vepskijale nacal'nijale şkolale: Nel'l'andele openduz vodele. 2 cast'. Leningrad: Kirja. - 93 lp.

Andrejev, F. A. 1937. Lugend knig: Kuumandele klassale nacal'nijale şkolale. Cast' 3. - Leningrad, Moskva: Gosudarstvennij openduz-pedagogiceskij izdatel'stv. - 124 lp.

Andrejev, F. A., N. I.Bogdanov, V. I.Petuhov, I. A. Silin 1933. Lugend knig toizele openduz vodele vepsoiden nacalnijas şkolas. Redaktor F. Andrejev. Leningrad: Kirja. - 88 lp. Internetis: http://fulr.karelia.ru/cgi-bin/flib/veps_book1.cgi (vaadatud märts 2012).

Andrejev, F., M. Hämäläinen 1936. Bukvar' vepsän şkolile. Moskva, Leningrad: Gosudarstvennij openduz-pedagogiceskij izdatel'stv. - 67 lp.

Internetis: http://fulr.karelia.ru/cgi-bin/flib/bukvar.cgi (vaadatud märts 2012).

Andrejeva, Alevtina 2003. Koivuine: Runod. Kuhmo: Juminkeko, Petroskoi: Periodika.- 127, [1] lp.

Andrejeva, I. F. 1936. Lugend knig: Ez'maizele klassale. Cast' 1. Moskva, Leningrad: Gosudarstvennıj openduz-pedagogiceskij izdatel'stv. - 105 lp. 
Apostoliden 1999 = Apostoliden tegod . Stokgol'm, Helsinki: Biblijan Kändmižen Institut, 1999. - $104 \mathrm{lp}$.

${ }^{\star}$ Ariste, Paul 1964. Vepsa muinasjutte: (Äänis- ja keskvepsa keelenäiteid). Töid läänemeresoome ja volga keelte alalt. Toimetaja: E. Pajusalu-Adler. Tallinn, lk 5-23.

Bašnin, Mihail 2003. Vanh zirkul = Старое зеркало: Стихи на вепсском и русском языках. Petroskoi, Periodika. - 63, [1] lp.

${ }^{*}$ Belõje $2010=$ Белье ночи $=$ Еджыд войяс $=$ Мӧдьь уйёс = Ош йюд влак

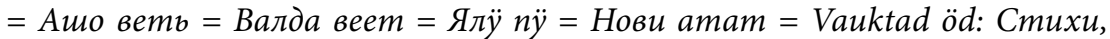
paccказы. Составитель Н. А. Обрезкова. Сыктывкар: Филиал ГРДНТ Финно-угорский культурный центр Российской Федерации. - 188, [2] с.

Bogdanov, N., M. Hämäläinen, A. Mihkijev 1932. Ez'mäine vepsiden azbuk $i$ lugendknig. Leningrad: Kirja. - $78 \mathrm{lp}$.

Internetis: http://fulr.karelia.ru/cgi-bin/flib/azbuka.cgi (vaadatud märts 2012).

Bogdanov, N., M. Loginov, G. Bol'şakov, V. Romanov, I. Andrejva, M. Sokolov. Lugend knig: Toizele klassale nacal'nijale şkolale. Cast' 2. Moskva, Leningrad: Gosudarstvennij openduz-pedagogiceskij izdatel'stv, 1936. - 124 lp.

Internetis: http://fulr.karelia.ru/cgi-bin/flib/veps_book2.cgi (vaadatud märts 2012).

Brodski, Igor 2000. Ičemoi londuz: Lugendkirj lapsile vepsän kelel. Toimitai: N. Zaiceva. Petroskoi: Periodika. - 103 lp.

Brodski, Igor 2002. Kalarand: Roman. (Juminkegon painduzed; 25) Kuhmo, Petroskoi: Juminkeko, Verso. - 146, [1] lp.

Brodski 2005 = Бродский И. В. Вепсско-русский, русско-вепсский словарь. Санкт-Петербург: Просвещение. - 256 с.

Evangelii 1993 = Evangelii Joannan mödhe. Stokgol'm, Helsinki, Biblijan Kändmižen Institut, 1993. - 86, [6] lp.

Evangelii 1996 = Evangelii Lukan mödhe. Stokgol'm, Helsinki: Biblijan Kändmižen Institut, 1996. - 94 lp.

Evangelii 1998 = Evangelii Matvejan mödhe. Stokgol'm, Helsinki: Biblijan Kändmižen Institut, 1998. - 97, [1] lp.

Ginijatullina, Marina, Nadežda Kukojeva 2008. Radlehtik: Vepsän kel' 1. Petroskoi. - 39, [1] lp. 
Grigor'jev, N. 1937. Pol'toşt' paginad: Dispetceran sanutez. Vepsän kelele perevodi M. Loginov. Moskva, Leningrad: Lapsiden literaturan izdatel'stv. - 38 lp.

Hämäläinen, M., F. Andrejev 1934. Vepskijan kelen grammatik. Leningrad: Kirja. -55 lp.

Hämäläinen, M., F. Andrejev 1935. Vepsän kelen grammatik kuumandele $i$ nel'l'andele klassale nacal'nijas şkolas. Leningrad: Kirja. - 61 lp.

Hämäläinen, M. M., F. A. Andrejev 1936. Vepsa-venähine vajehnik. Moskva, Leningrad: Gosudarstvennij openduz-pedagogiceskij izdatel'stv. - 75 lp.

Internetis: http://fulr.karelia.ru/cgi-bin/flib/slovar.cgi (vaadatud märts 2012).

Iče 2011 = Iče kulin, iče nägin: Vepsläižed sarnad = Сам слымал, сам видел: Вепсские сказки. Составила: О. Жукова. Petroskoi: Verso, 2011. - 43, [1] lp.

Iisusan 1991 = Iisusan elo. Stokgol'm, Helsinki: Biblijan Kändmižen Institut, 1991. - 61, [1] lp.

Iisusan 1994 = Iisusan elo. 2., kohetud painuz. Stokgol'm, Helsinki: Biblijan Kändmižen Institut, 1994. - 61, [1] lp.

${ }^{*}$ Inno, Helvi 1991. Ensimmäisen vepsäläisen sanakirjan laatija. - Carelia, n-ro 8, s. 112-118.

${ }^{\star} J$ egorova, Svetlana 1997. Lasten raamattu - askel kohti kirjakieltä. - Carelia, n-ro 1, s. 120-121.

Jugras 2006 = Jugrasta Balatonille: suomalais-ugrilaista runoutta karjalan, suomen ja vepsän kielillä. Jugras Balatonah sah: suomelas-ugrilazii runoloi karjalan, suomen da vepsän kielil. Составители: А. Л. Волков и А. И. Мишин. Petroskoi: Periodika, 2006. - 221, [3] s.

Kalevala 2003 = Kalevala: A. Mišinan i E. Kiurun kompozician mödhe. Vepsäks om kändnu N. Zaiceva. Kuhmo, Petroskoi: Juminkeko, Periodika, 2003. - 164 lp.

Kettunen, Lauri 1920. Näytteitä etelävepsästä 1. (Suomi; 4: 18.) Helsinki: Suomalaisen Kirjallisuuden Seura. - $126 \mathrm{~s}$.

Kettunen, Lauri 1925. Näytteitä etelävepsästä 2. (Suomi; 5: 4) Helsinki: Suomalaisen Kirjallisuuden Seura. - 146 s.

Kipinä: Vepsläine kibin: [Laps'kulehtez]. Petroskoi: Periodika, 2011, n 1, 6, sügüz'ku, tal'vku. 
Internetis: http://kipina.rkperiodika.ru/arhiv.php?year=0000 (vaadatud märts 2012).

Kočerina, J. J. 2004. Opendam vepsän kel't: Openduzozuteline abukirj lapsile, alaopenikoile i kazvatajile = Учимся говорить по-вепски. Petroskoi: Periodika. - 194, [1] lp.

Kodima: [Lehtez]. Petroskoi: Periodika, 1992-2011, 225 nomerad. Internetis: http://kodima.rkperiodika.ru/index.php?option=com_arhive\&view $=$ arhive\&id (vaadatud märts 2012).

Kodima, Vepsänma. Toimitai: Markku Nieminen. (Juminkegon paindused; 32.) Kuhmo, Petroskoi: Juminkeko, Karelija, 2003. - 69, [3] lp.

Kodirandaine 1996 = Kodirandaine. Runod i sanutesed vepsän kelel. Petroskoi, Karjala, 1996. - 125, [1] lp.

Kottina, A., A. Maksimov, N. Zaiceva 1998. Meiden sana: Lugendkirj augotižškolan täht. Petroskoi: Periodika. - 96 lp.

Kukojeva, N. А., М. В. Ginijatullina $2007=$ Кукоева, Н. А. Vepsän kel' 1: Учебник для 1 класса общеобразовательных учреждений. Петрозаводск: Периодика, 2007. - 39, [1] с.

Kukojeva N. A., M. B. Ginijatullina 2009. Vepsän kel': 2. klass. Petroskoi: Periodika. - 69, [2] lp.

Lapsiden 1996 = Lapsiden Biblii: Biblijan sanutesed kuvidenke. Tegijad: Borislav Agapovič i Vera Mattelmäki. Vepsäks om kändnu Nina Zaiceva. Stokgol'm, Helsinki: Biblijan Kändmižen Institut, 1996. - 542 lp.

${ }^{*}$ Kuum öö: Soome-ugri rahvaste tänapäeva luulet $=$ Palavu $\ddot{u} о \ddot{~}=$ Kuuma yö = Пӧсь вой $=$ Пьм оц $=$ Пӧсь уй =Шокшо йуд = Пфи ве =Пфи илядь = Hиl $\ddot{о}=$ Ядембада пи. Koost. ja tlk. Arvo Valton, Jaan Õispuu. Toim. Nadja Pchelovodova. Tallinn: Kirjastuskeskus, 2006. 777, [5] lk.

Lardot, R. M. 2001. Däižed lindud lanktoba oksilpei = Jäätyneet linnut putoavat oksiltaan. Kääntäneet Maria Zaiceva, Miikul Pahomov, Leo Maltšukov. Jyväskylä: Atena. - 96 lp.

Lingvistine termišt $=$ Лингвистическая терминология на вепсском языке. Petroskoi: Periodika, 2001. - 19, [1] lp.

Lonin, R[ürik]. 2000a. Minun rahvhan fol'klor. Petroskoi: Periodika. - 108 lp.

Lonin, R[ürik]. 2000b. Lühüdad pajoižed. Om keradanu R. Lonin. Muzik: Irina Semakova. Petroskoi, 2000. - 70 lp. 
Lukkonen, Vladimir 1992. Ozatoi kalatez: [Komiks]. Perevodiba vepsän kelele N. Zaiceva. Petroskoi: Karjala. - 14 lp.

${ }^{*} L^{\prime} \ddot{о т j и ~} 2008=$ Льӧм ю = Льӧмпуа юок = Ломбо эн'ер = [?] Zelnicemeggyespatakoska $=$ Льöмny uyp $=$ Toomingajõgi $=$ Tuomijoki $=$ Tom' jogi :

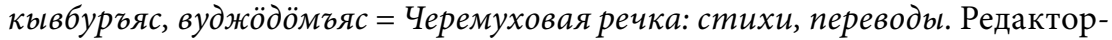
составитель: Е. В. Козлова. Перевод: В. В. Тимин и др. - Сыктывкар: Кола, 2008. - 254, [1] c.

*Lönnrot, Elias 1853. Om det Nord-Tschudiska språket: Akademisk Afhandling. Helsingfors. $-54 \mathrm{~s}$.

${ }^{\star}$ Lönnrot, Elias 1991. Om det Nord-tschudiska språket. - Valitut teokset 3: Kirjoitelmia ja lausumia.Suomalaisen Kirjallisuuden Seuran toimituksia 551. Helsinki-Pieksamäki, s. 41-74.

${ }^{*}$ Lönnrot, Elias 2002. Om det Nord-tschudiska språket: Elias Lönnrotin väitöskirja vepsän kielestä vuodelta 1853. (Juminkeon julkaisuja; 24) [Kuhmo:] Juminkeko, 2002. - 53 s.

Maksimova, Kottina 1992 = Максимова Р. Ф., Э. В. Коттина. Букварь: Для 1 класса вепсских школ. Санкт-Петербург: Просвещение. - 127 с.

Markan 1992= Markan Evangelii. Stokgol'm, Helsinki: Biblijan Kändmižen Institut. 1992. - 83, [2] lp.

Mehen = Mehen oiktuziden ühthine deklaracii: Om todištadud i ezitadud Päassamblejan rezolucijal 217 A (III) 10. tal'vkud v. 1948. Перевод: Ольга Жукова. Москва: Права человека, 2009. 12 lp.

Mel'nik, E. L. 2000. Ümbrišt: Tölehtik augotižškolan openikoile= Окружающая среда: Рабочая тетрадь для начальных школ. (Моя Карелия) Petroskoi: KGPU. - 48 lp.

Melentjeva, L. 1994. Soitoine: Vepsän randan lapsiden pajod. Vepsän kelen redaktor: Nina Zaiceva. Muzikan redaktor Irina Semakova. Petroskoi, Karjala. $-45 \mathrm{lp}$.

${ }^{*}$ Mišin, Armas 2005. Vepsäläinen kirjallisuus ammattikirjailijan silmin. Vepsä: Maa, kansa, kulttuuri. Toimittanut Lassi Saressalo. Tampere, Helsinki: Tampereen museot, Suomalaisen Kirjallisuuden Seura, s. 193-210.

*Mošnikov, Oleg 2007. “Jäätyneet linnut”. - Carelia, n-ro 9, s. 118-120. 
*Mullonen $1967=$ Муллонен, М. Вепсская письменность. - Прибалтийскофинское языкознание: Вопросы фонетики, грамматики и тексикологии. Ленинград: Наука, с. 195-109.

Näytteitä vepsän murteista. Keränneet ja julkaisseet Lauri Kettunen ja Paavo Siro. Suomalais-Ugrilaisen Seuran toimituksia 70. Helsinki: Suomalais-Ugrilainen Seura, 1935. - $193 \mathrm{~s}$.

Näytteitä äänis- ja keskivepsän murteista. Keränneet E. N. Setälä ja J. H. Kala. Julkaissut ja suomentanut E. A. Tunkelo. Suomalais-Ugrilaisen Seuran toimituksia 100. Helsinki: Suomalais-Ugrilainen Seura, 1951. - 621, [1] s.

*Pekkanen, Inka 2005. Raamattua vepsäksi. - Vepsä: Maa, kansa, kulttuuri. Toimittanut Lassi Saressalo. Tampere, Helsinki: Tampereen museot, Suomalaisen Kirjallisuuden Seura, s. 163-170.

Popova, N. S. 1933a. Arifmetikan openduzkirj nacal'nijale şkolale: Ez'mäine voz' opendust. Cast' 1 . Venäkelelpei perevodi N. I. Bogdanov. Leningrad: Kirja. $-70 \mathrm{lp}$.

Popova, N. S 1933b. Arifmetikan openduzkirj nacal'nijale şkolale: 2. voz'opendust. Leningrad: Kirja. -73 lp.

Popova, N. S. 1934a. Arifmeticeskijoiden zadacuiden i har'goitusiden keraduzkirj: Kuumandele openduz'vodele nacal'nijale şkolale. Cast' 1. Leningrad: Kirja. $-58 \mathrm{lp}$.

Popova, N. S. 1934b. Arifmeticekijoiden zadacuicen i har'goidusiden keraduzkirj: 4 openduzvoz' nacal'nijale şkolale. Cast' 2. Leningrad: Kirja. - 69 lp.

Popova, N. S. 1934c. Arifmetikan openduzkirj: 2 openduzvoz'. Leningrad: Kirja. $-74 \mathrm{lp}$.

Popova, N. S. 1934d. Arifmetikan openduzkirj: Nacal'nijale şkolale: 3-le i 4-le openduzvozile. 3. cast'. Leningrad: Kirja. - 69 lp.

Popova, N. S. 1936. Arifmetikan openduz knig ez'mäizele klassale nacal'nijale şkolale. Cast' 1. Moskva, Leningrad: Gosudarstvennij openduz-pedagogiceskij izdatel'stv. -64 lp.

Popova, N. S. 1937a. Arifmeticeskijoiden zadacuiden i har'goidusiden keraduz knig: 3-le klassale nacal'nijan şkolan. Cast' 1 . Vepsän kelele perevodi M. Loginov. Leningrad, Moskva, Gosudarstvennij openduz-pedagogiceskij izdatel'stv. -49 lp. 
Popova, N. S. 1937b. Arifmetikan openduz knig: Toizele klassale nacal'nijale şkolale. Cast' 2. Perevodi N. I. Bogdanov. Leningrad, Moskva: Gosudarstvennij openduz-pedagogiceskij izdatel'stv. - $69 \mathrm{lp}$.

Popova, N. S. 1937c. Arifmetikan openduz knig nacal'nijale şkolale: 3-le i 4-le klassoile. Cast' 3. Perevodi V. M. Romanov. Leningrad, Moskva: Gosudarstvennij openduz-pedagogiceskij izdatel'stv. - 57 lp.

Popova, V., N. Zaiceva 2004. Petroskoi. - 136 lp.

Programmad 1937 = Programmad vepsän nacal'nijale şkolale: Coma-kirjutez. Leningrad, Moskva: Gosudarstvennij openduz-pedagogiceskij izdatel'stv, 1937. -28 lp.

*Prozes, Jaak 2012. Rahvaloendus ja soome-ugri. - Sirp, 23. III.

Rogozina, V., N. Zaiceva 2004. Vepsan kelen harjoituzkogomuz: Fonetik. Nimiformad. Adverbat. Abusanad. Petroskoi: Petroskoin valdkundan korgedškol. $136 \mathrm{lp}$.

*Salve, Kristi 1994. Vepslaste “Kodima”. - Keel ja Kirjandus, nr 5, lk 319-320.

*Salve, Kristi 2004. "Kalarand": Vaatlusi ja võrdlusi: [Retsensioon]. - Keel ja Kirjandus, nr 4, lk 306-309.

${ }^{\star}$ Savolainen, Mikko 1998. Vepsä: Vepsänmaa $=$ Vepsian land $=$ Vepsänma $=$ Vepslandia. Historiateksti: Kaija Heikkinen, Aleksandr Saksa. Käännökset: Nina Zaiceva, Markku Tuomi, Aleksandr Saksa. Oulu: Atena. - 142 s.

Silakova, Natalia. Todesižed sebranikad.Vepsäks kändi Marina Ginijatullina. Petroskoi: Periodika, 2006. 31, [1]lp.

Silakova, N[atalia]. 2009. Vauged ö. Vepsäks kändi Marina Ginijatullina. Petroskoi : [s. n.], 2009. - 31, [1] lp.

Skazki 1993 = Сказки, рассказы, пословицы и стихи на вепсском языке. Сборник. Составитель: Л. Ф. Алексеева. Петрозаводск: Карельский институт усовершенствования учителей. - $34 \mathrm{c}$.

Sopostovitel'no 2007 = Сопоставительно-ономасиологический словарь диалектов карельского, вепсского и саамского языков. Под общей редакцией Ю. С. Елисеева и Н. Г. Зайцевой. Составители: А. П. Баранцев и др. Петрозаводск: Карельский научный центр РАН, 2007. - 343 с.

*Spiridonova 2000 = Спиридонова, И. А. Вепсская литература: Проблемы становления. - История литературы Карелии 3. Петрозаводск: Карельский научный цнетр РАН, с. 391-419. 
Strogalščikova, Zinaida 2008.Vepsläižed: Istorii-etnografine tedosanutez. Kändai: Nina Zaiceva. Toimitajad: Jelizaveta Haritonova, Olga Žukova. (Bibliotheca fenno-ugrica.) Petroskoi: Periodika. - 252 lp.

Ščerbakova, Tamara, L'udmila Aleksejeva 2010. An'oile da Ven'oile vunukkazil armahil = An'oile da Ven'oile armhile vonukoile. Петрозаводск: Verso. - 93, [1] lp.

Školvaihišt = Школьная пексика на вепсском языке. Составитель: Е. Харитонова. Petroskoi: Periodika, 2001. - 55, [1] lp.

*Zaiceva 1981 = Зайцева, М. И. Грамматика вепсского языка: (Фонетика и морфология). Ленинград: Наука. - 360 с.

*Zaiceva, Nina 1989. Kieli on säilytettävä. - Punalippu, n-ro 2, s. 129-132.

Zaiceva, N[ina] 1995. Vepsän kelen grammatik: (1. Nimiden kändluz). Petroskoi. -114 lp.

*Zaiceva 1997 = Zaitseva, Nina. Vepsä taistelee olemassaolostaan. - Carelia, n-ro 1, s. 116-119.

Zaiceva N[ina] 2000a, vt Zaikov jt 2000.

*Zaiceva 2000b = Зайцева, Н. Г. Вепсская литература 1990-х годов. История литературы Карелии 3. Петрозаводск: Карельский научный цнетр РАН, с. 391-419.

Zaiceva, N[ina]. 2003. Vepsän kelen grammatik: Teoretine openduzkirj 5-9 klassoile. Petroskoi: Periodika. - $240 \mathrm{lp}$.

Zaiceva, Nina 2005a. Izo Lizoi. Petroskoi: Periodika. - 32 lp.

*Zaiceva, Nina 2005b. Vepsäläinen kirjallisuus tiensä alussa. - Vepsä: Maa, kansa, kulttuuri. Toimittanut Lassi Saressalo. Tampere, Helsinki: Tampereen museot, Suomalaisen Kirjallisuuden Seura, s. 181-192.

Zaiceva, Nina 2008. Vauktan unen süles. Петрозаводск: Периодика. - 90, [2] lp.

Zaiceva, Mullonen 1969 = Зайцева, М., М. Муллонен. Образцы вепсской речи. Ленинград: Наука, 1969. - 296 с.

Zaiceva, Mullonen 1972 = Зайцева, М. И., М. И. Муллонен. Словарь вепсского языка. Ленинград: Наука, 1972. - 745 с.

Zaiceva, N., M. Mullonen 1991a. Abekirj. Petroskoi: Karjala. - 94 lp. 
Zaiceva, N., M. Mullonen 1991b. Lugem i pagižem vepsäks: Lugendkirj toižele klassale. Petroskoi: Karjala. - 103 lp.

Zaiceva, N., M. Mullonen 1994. Ičemoi lugemišt: Vepsän kelen lugendkirj 3.-4. klassale. Petroskoi: Karjala. - 126, [2] lp.

Zaiceva, N., M. Mullonen 1995. Vepsä-venälaine, venä-vepsläine vajehnik: läz 14000 sanad= Вепсско-русский, русско-вепский учебный словарь: около 14000 слова. Petroskoi: Karjala. - 190, [2] lp.

Zaiceva, Mullonen 2009 = Зайцева, Н. Г., М. И. Муллонен Новый руссковепсский словарь $=U z^{\prime}$ venä-vepsläine vajehnik. Петрозаводск: Периодика. $-516,[3]$ c.

Zaiceva, Mullonen 2010 = Зайцева, Н. Г. Новый вепсско-русский словарь = $U z^{\prime}$ vepsä-venalaine vajehnik. Петрозаводск: Периодика. - 509, [1] с.

Zaikov, P., L. Rugojeva, O. Gorškova 2000. Harjotuksie vienankarjalaksi: (Verbi. Infinitiivit. Patisiipit. Partikkelit). Zaiceva N. 2000. Vepsän kelen grammatik: (2. Verboiden kändluz. Verboiden nimiformad. Kändamatomad sanad). Петрозаводск: Петрозаводский государственный университет. - 230, [2] lp. [Vepsän kelel: lp. 113-230].

Žukova, Ol'ga 2011. Mäthudel: runod da pajoižed lapsile. Petroskoi: Periodika. -15 , [1] lp.

Terehova, L. G., V. G. Erdeli 1934. Geografijan openduzkirj nacal'nijale şkolale: Kuumanz' openduz voz'. Cast' 1 . Leningrad: Kirja. - 75 lp.

Terehova, L. G., V. G. Erdeli 1936a. Geografij:Openduz knig kuumandele klassale nacal'nijas şkolas. Cast' 1. Perevodiba I. F. Andrejeva, N. I. Bogdanov, M. G. Loginov, V. M. Romanov. Moskva, Leningrad: Gosudarstvennij openduz-pedagogiceskij izdatel'stv. - $128 \mathrm{lp}$.

Terehova, L. G., V. G. Erdeli 1936b. Geografij: Openduz knig nel'l'andele klassale nacal'nijas şkolas. Cast' 2. Perevodiba vepsän kelele F. Andrejev, N. Bogdanov, M. Loginov, V. Romanov. Moskva, Leningrad: Gosudarstvennij openduz-pedagogiceskij izdatel'stv, 1936. - 135 lp.

Tetyrev, V. A. 1934. Jestesvoznanijan openduzkirj nacal'nijale şkolale: 3 voz' opendust. Cast' 1 . Leningrad: Kirja. - 76 lp.

Tetyrev, V. A. 1935. Jestestvoznanijan openduzkirj nacal'nijale şkolale: 4 openduz voz'. Cast' 2. Leningrad: Kirja. - $115 \mathrm{lp}$. 
Tetyrev, V. A. 1937a. Jestestvoznanij: Openduz knig nacal'nijan şkolan kuumandele klassale. Cast' 1. Vepsän kelele perevodi I. Andrejeva. Leningrad, Moskva: Gosudarstvennij openduz-pedagogiceskij izdatel'stv, 1937. - 112 lp.

Tetyrev, V. A. 1937b. Jestestvoznanij: Openduz knig nacal'nijan şkolan 4-le klassale. Cast' 2. Perevodiba I. Andreeva, N. Bogdanov i V. Romanov. Leningrad, Moskva: Gosudarstvennij openduz-pedagogiceskij izdatel'stv, 1937. - 132 lp.

Uspenski 1913 = Успенский Л. Русско-иудский словарь с некоторыми грамматическими указаниями. Санкт-Петербург. - 43 с.

Internetis: http://fulr.karelia.ru/cgi-bin/flib/chudoslovar.cgi (vaadatud märts 2012).

$U z^{\prime}$ Zavet. Stokgol'm, Helsinki: Biblijan Kändmižen Institut, 2006. - 614 lp.

${ }^{*}$ Uurali keelte sõnastik: Eesti, lìvõkēl, võro, vad'd'a, ižora, suomi, karjala, vepsä, sámegiella, эрзянь, мокщень, олык мари, курык мари, коит, удмурт, ханты, ма̄ньси, magyar, ненеияя. Koost. Valt Ernštreit jt. Toim. Eva Saar. Tallinn: SURI, 2004. - 139, [5] lk.

${ }^{*}$ Uurali keelte sõnastik: Eesti, vad'd'a, võro, lìvõ, ižora, suomi, karjala, vepsä, sámegiella, эрзянь, мокшень, олык марла, курык марла, коми, удмурт, ханты, ма̄ньси, magyar, ненеия.2., parandatud ja täiendatud trükk. Koost. Natalja Abrosimova jt. Toim. Eva Saar. Tallinn: Fenno-Ugria Asutus, 2011. 143, [1] lk.

Venä-vepsläine abupaginkirj $2009=$ Русско-вепсский разговорник. Составители: Н. Г. Зайцева, О. Ю. Жукова. Под общей редакцией Н. Г. Зайцевой. Петрозаводск: Периодика, 2009. - 222, [2]c.

*Vepsa $1992 a$ = Vepsa vanasõnad: Eesti, vadja, liivi, karjala ja vene vastetega. 1. osa. Koost. Vaina Mälk, Anne Hussar, Aime Kährik, Tiit-Rein Viitso. Toim. Arvo Krikman, Aime Kährik, Vaina Mälk, Tiit-Rein Viitso. Tallinn: Eesti Teaduste Akadeemia, 1992. - $352 \mathrm{lk}$.

${ }^{*}$ Vepsa $1992 b$ = Vepsa vanasõnad: Eesti, vadja, liivi, karjala ja vene vastetega. 2. osa. Koost. Vaina Mälk, Anne Hussar, Aime Kährik, Tiit-Rein Viitso. Toim. Arvo Krikman, Aime Kährik, Vaina Mälk, Tiit-Rein Viitso. Tallinn: Eesti Teaduste Akadeemia, 1992. - lk 353-681.

Vepsa $1993={ }^{*}$ Vepsa muinasjutte. Kogunud ja raamatuks seadnud Kristi Salve. Tallinn: Perioodika, 1993. - 78, [1] lk.

Vepsläine 2006 = Vepsläine kalendar' $=$ Вепсский календарь: 2009-2010. Составители: Ю. Наумова и др. Петрозаводск, 2009. - 24 с. 
Vepsän 2004 = Vepsän kelen radlehtik: 2. voz: К букварю Н. Г. Зайцевой и М. М. Муллонен “Abekirj”. Составила: Е. Е. Кочерина. Petroskoi, 2004. - 44 lp.

Vepsän kelen uz' vaihišt. Составили М. Б. Гиниятуллина, Е. Е. Харитонова, Н. Г. Зайцева, М. И. Муллонен. Бюллютень термино-орфографической комиссии 9. Petroskoi: Periodika, 2004. - 189, [3] lp.

Vepsän 1996 = Vepsän rahvhan sarnad. Составители: Н. Ф. Онегина, М. И. Зайцева. (Памятники фольклора Карелии.) Petroskoi: Karjala, 1996. - 261 lp.

Vepsänman 2006 = Vepsänman sarnad. Kerazi vepsläižidenno oldes vodel 1842 Elias Lönnrot. Toimitai: Nina Zaiceva. [Kuhmo], Petroskoi: Juminkeko, Verso, 2006. - 39, [1] lp.

Verez tullei: Vauktan Vesin runosanad. Составитель: Н. Г. Зайцева. Petroskoi: Periodika, 2006. - 110 lp.

Verez tullei 2011: Al'manah. Toimitajad: Larissa Cirkova jt. Petroskoi: Periodika, 2011. - 160 lp.

*Virtaranta, Pertti 1967. Lähisukukielten lukemisto. (Suomalaisen Kirjallisuuden Seuran toimituksia; 280) Helsinki: Suomalaisen Kirjallisuuden Seura.

*Õispuu, Jaan 2003. Karjala kirjandus ja keelepoliitika. - Keel ja Kirjandus, nr 7, lk 509-530.

Ä̈nisvepsän näytteitä. Keränneet ja julkaisseet A. Sovijärvi ja R. Peltola. (Suomalais-Ugrilaisen Seuran toimituksia; 171.) Helsinki: Suomalais-Ugrilainen Seura, 1982. - 7, 171, [1] s.

\section{Summary}

\section{On literature in Vepsian language}

The paper gives a survey of the literature in the Vepsian language based on functional classification. 6 books containing Vepsian texts (incl. a dictionary) were printed in the preliminary period of the Vepsian literature (1853-1931). 32 books in Vepsian were published during the first period (1932-1937), most of them (28) school 
textbooks. On the average, 4.6 books were published per year. Only 4 books came out in the intermediate period (1938-1988). 66 books in Vepsian have been published during the second period (since 1989). 27 of them belong to the belles-lettres, 9 to sacral literature and 9 to reference literature. There are 17 textbooks. At present, on the average of 3 books are published per year in Vepsian language. Unlike during the the first period, much attention is paid to publishing of the belles-lettres and the sacral works. Contemporary Vepsian books are beautiful. The magazine "Kipinä" ('The Sparkle') in Vepsian for children has been issued since 2011 and the bilingual newspaper "Kodima" ('The Native Place') since 1993.

Key words: literature in Vepsian, books, periodicals, functional classification of literature, belletristics 